\title{
REZENSIONEN
}

\section{Bundespräsidenten: Biographien über Bürger, Pastoren und Schnäppchenjäger}

Heidemanns, Martin und Nikolaus Harbusch: Affäre Wulff. Bundespräsident für 598 TageDie Geschichte eines Scheiterns, Schwarzkopf \& Schwarzkopf, Berlin 2012, 335 Seiten, $€ 19,95$.

Robers, Norbert: Joachim Gauck - Vom Pastor zum Präsidenten. Die Biografie, 2. Auflage, Koehler \& Amelang, Leipzig 2012, 240 Seiten, € 19,95.

Merseburger, Peter: Theodor Heuss. Der Bürger als Präsident. Biographie, DVA, München 2012, 672 Seiten, $€ 29,99$.

Während das im November 2013 begonnene Verfahren gegen den vormaligen Bundespräsidenten Christian Wulff im Juni 2014 ein vor allem für die Staatsanwaltschaft unrühmliches Ende fand und sich das BVerfG gleich doppelt mit dem Bundespräsidenten - genauer: dem Wahlmodus in der Bundesversammlung sowie seiner Pflicht zur Überparteilichkeit befasst hat, reibt man sich gleichermaßen verwundert wie ermattet die Augen. Denn wer hätte je gedacht, dass das Amt des Bundespräsidenten noch einmal solche Aufmerksamkeit wie in den letzten Jahren auf sich ziehen könnte, und vor allem: auf diese Weise. Und doch, die letzten Amtsinhaber sorgten (und sorgen) mit jeweils ganz unterschiedlichen Akzentuierungen dafür, dass das oft als weitgehend bedeutungslos charakterisierte Amt wieder in das Zentrum öffentlicher Debatten geriet. Machte Horst Köhler damit Furore, dass er sich zunehmend als „außerparlamentarische Opposition“ inszenierte, die Ausfertigung von Gesetzen verweigerte und zuletzt zermürbt von heftiger Kritik vom Amt zurücktrat, sorgte sein Nachfolger Christian Wulff, dessen Wahl in der Bundesversammlung bereits nur stotternd gelang, für ganz andere Schlagzeilen. Angetreten als jüngster Bundespräsident aller Zeiten, verhedderte er sich in seiner nur 598 Tage währenden Amtszeit in ein undurchsichtiges und bis in seine Zeit als Landespolitiker und Ministerpräsident zurückreichendes Beziehungsnetz, in dem Kredite, finanzielle Vergünstigungen und Zuwendungen den Vorwurf der Vorteilsannahme und Vorteilsgewährung im Amt befeuerten - was nach einer deplorablen Informations- und Rechtfertigungspolitik, Teilgeständnissen und öffentlichen Exkulpierungsversuchen sowie immer absurderen Investigativexzessen der Presse (Stichwort: Bobby-Car) schließlich darin kulminierte, dass die Staatsanwaltschaft am 16. Februar 2012 die Aufhebung der Immunität von Christian Wulffbeantragte, um Ermittlungen gegen ihn führen zu können. Der Rücktritt am nächsten Tag war der vorläufige Endpunkt eines politischen und persönlichen Dramas, das die Bundesrepublik Deutschland über Monate beschäftigte und seinen juristischen Abschluss im Juni 2014 fand, als die Staatsanwaltschaft auf Revision gegen das Urteil verzichtete, mit dem Wulff am Ende des am 14. November 2013 vor dem Landgericht Hannover begonnenen Prozesses freigesprochen worden war. Nach all dem kam Wulffs Nachfolger Joachim Gauck nahezu die Rolle eines „Erlösers“ zu, der dem Amt des Bundespräsidenten die ihm zukommende Würde zurückgeben könne, nachdem (wieder einmal) darüber diskutiert wurde, ob die Bundesrepublik Deutschland 
dieses Amt denn tatsächlich noch brauche. Diese Frage wiederum beantwortet man gern mit dem gelegentlich verklärenden Verweis auf „leuchtende“ Beispiele präsidialer Amtsführung, nicht zuletzt durch den ersten Bundespräsidenten Theodor Heuss.

Wulff, Gauck, Heuss - so unterschiedlich diese Bundespräsidenten, so unterschiedlich auch die drei Bücher, um die es hier geht. Heidemanns und Harbusch, beide Journalisten bei BILD, wurden für ihre Recherche zur Kredit-Affäre Wulff am 11. Mai 2012 mit dem Henri-Nannen-Preis ausgezeichnet. Im vorliegenden Band präsentieren sie eine um zahlreiche Dokumente, Korrespondenzen und Kontextschilderungen ergänzte Chronik der von ihnen ins Rollen gebrachten Wulff-Affäre, deren Lektüre auch mit zeitlichem Abstand noch verstörend wirkt. Keine Frage: Das ist spannend geschrieben, der unwiderstehliche und unerbittliche Sog, den diese Ereignisse entwickelten, wird deutlich, und das ist dramaturgisch sicher ebenso gewollt wie die oft durchscheinende Befriedigung und Betonung, dass es die BILD ist, die hier pro bonum commune investigativ renommieren darf. Je weiter die Chronik aber voranschreitet, desto mehr möchte man eigentlich das Buch weglegen, weil sich jene quälende Mischung aus Fassungslosigkeit und Fremdschämen wieder einstellt, die bereits um sich griff, als die Affäre in vollem Gange war und sich über Weihnachten und Neujahr hinzog. Denn: Es macht schlichtweg keinen Spaß, dieser (Selbst-)Demontage des Amtsinhabers und des Amtes beizuwohnen. Über letzteres erfährt man hier übrigens nichts Relevantes, außer dass es im besten Sinne des Wortes ein „Amt“ und somit auf Zeit verliehen ist, damit aber latent der öffentlichen Kontrolle und Kritik ausgesetzt ist - womit man als Amtsinhaber auch umgehen können sollte.

Vor dem Hintergrund der Performanz von Christian Wulffim Amt musste seinem Nachfolger Joachim Gauck geradezu die oben erwähnte Erlöserrolle zufallen - und es entbehrt nicht der Ironie, dass ausgerechnet Gauck, gegen den Wulffin einen dritten Wahlgang der Bundesversammlung musste, nunmehr von der FDP - überraschend für Angela Merkel und die Union - auf einmal als präsidial erachtet wurde, wodurch die Kanzlerin nicht unerheblich düpiert wurde. Rückblickend fällt jedenfalls auf, wie oft die an der Person Gaucks sich festmachenden Heilserwartungen für das öffentlich zu rehabilitierende Amt des Bundespräsidenten mit dem Totalschaden seines Vorgängers und dessen Stromlinienförmigkeit begründet wurden, während sich seine Vita durch Brüche, seinen persönlichen Werdegang in der DDR sowie auf dem Weg zur und nach der Deutschen Einheit auszeichne. Die nunmehr in zweiter Auflage vorliegende Biografie von Norbert Robers gibt Gelegenheit, sich von der Stichhaltigkeit dieser Begründungen zu überzeugen. Sie gibt einen gut lesbaren Einblick in den Lebenslauf des heutigen Bundespräsidenten in der vormaligen DDR und als Leitfigur des von Rostock ausgehenden Bürgerprotests 1989, spart dabei persönlich-private Aspekte nicht aus und räumt insbesondere auch der Entstehung und Arbeit der „GauckBehörde" sowie der damit verbundenden Tätigkeit ihres Namensgebers breiten Raum ein. Hier sind die fast schon vergessenen Kontroversen um die IM-Vergangenheiten von Manfred Stolpe und Gregor Gysi erwähnenswert, die von Robers noch einmal mit Blick auf Gaucks Einlassungen hierzu rekonstruiert werden. Im letzten Teil des Buches mit dem Titel „Der politische Missionar“ rückt dann auch der Inhaber des Amtes des Bundespräsidenten in den Vordergrund. Gaucks Stärken werden hier vor allem in der Parteienferne, Eigenständigkeit und non-konformen Biographie sowie in seiner pastoralen Gabe des Wortes und der Rede gesehen, die ihn gerade vor dem Hintergrund der beiden Amtsvorgänger zu einer Art präsidialen „Traumkandidaten“ der ganzen Republik werden ließen - hier geht Robers allerdings gelegentlich die Distanz verloren. Aber wenn man schon einmal bei der Stilisie- 
rung leuchtender Beispiele für das Amt des Bundespräsidenten ist, dann führt kein Weg an Theodor Heuss vorbei, dem nunmehr auch Peter Merseburger (und zuletzt Joachim Radkau) eine neue Biographie gewidmet hat.

Merseburger, der bereits respektable Biographien über Kurt Schumacher, Willy Brandt und Rudolf Augstein vorgelegt hat, bietet eine gut geschriebene, in zehn chronologische Kapitel gegliederte Schilderung des Lebens von Heuss, die den politischen Menschen und Privatmann, den politischen Redner und natürlich den ersten Bundespräsidenten lebendig werden lässt. Man wird darin nichts wesentlich Neues erfahren - aber Werdegang, Prägungen durch den Vater in Kindheit und Jugend, die Studentenzeit unter dem Einfluss seines Doktorvaters Lujo Brentano und die Entwicklung zum engagierten Liberalen und Patrioten bei der DDP, das hartnäckige Streben und Erlangen eines Reichstagmandats sowie die kritisch-mutige Auseinandersetzung mit Hitler speziell 1932 werden ebenso geschildert wie die unglückselige Zustimmung von Heuss zum Ermächtigungsgesetz am 23. März 1933, die an ihm haften blieb und die er sich auch selbst nicht nachsehen wollte. Besonders interessant mit Blick auf das Amt des Bundespräsidenten sind die beiden letzten Kapitel des Buches - hier wird die Biographie auch zu einer interessanten Studie über den Bundespräsidenten als politischen Akteur in der Kanzlerdemokratie Adenauers. Heuss' Anteil an der Neubegründung einer neuen demokratischen Kultur in der Bundesrepublik sowie die durch ihn personalisierte Repräsentation eines neuen Deutschland gegenüber dem skeptischen Ausland würdigt Merseburger dabei ebenso, wie er kleine persönliche Eitelkeiten und Selbstgefälligkeiten nicht unterschlägt. Einmal mehr zeigen diese drei Bücher, dass es den Phänotypus des idealen Bundespräsidenten nicht gibt, sondern dessen Leistung im Amt sehr stark von Person und Kontext geprägt wird.

Roland Lhotta

\section{Professor, Politiker, Publizist - und Organist: exquisite Autobiographie eines einfluss- reichen „praktischen Philosophen“ der westdeutschen Demokratie}

Maier, Hans: Böse Jahre, gute Jahre. Ein Leben 1931 ff., Verlag C.H. Beck, München 2013, 420 Seiten mit 68 Abbildungen, $€ 14,95$.

Den jüngeren Lesern dieser Zeitschrift dürfte er nur noch von Ferne her etwas sagen: Hans Maier, einer der herausragenden Kulturpolitiker der alten Bundesrepublik und von 1970 bis 1986 bayerischer Kultusminister. Als Leser seiner faszinierenden, stilistisch bravourösen Autobiographie fühlt man sich gleich dreifach in längst vergangene alte Welten zurückversetzt: zunächst ganz sprichwörtlich in die „Freiburger Welt“ der Kriegs- und Nachkriegsjahre (Erster Teil, S. 9 - 121), sodann in die bewegte Zeit der 1960er bis 1980er Jahre, als in der alten Bundesrepublik die großen kultur-, bildungs- und geschichtspolitischen Kontroversen ausgetragen wurden (Zweiter Teil, S. 123 -311), schließlich in metaphorischem Sinne in eine gute alte Zeit, als Politiker nebenher noch ein ausgesprochen interessantes, keineswegs „ganz gewöhnliche(s) Leben“ als Homme de Lettres, umtriebiger Wissenschaftler, engagierter Katholik und begeisterter Organist führten (passim und Dritter Teil, S. 313 - 404). Maier war einer der wenigen Politiker der alten Bundesrepublik, die bruchlos von 